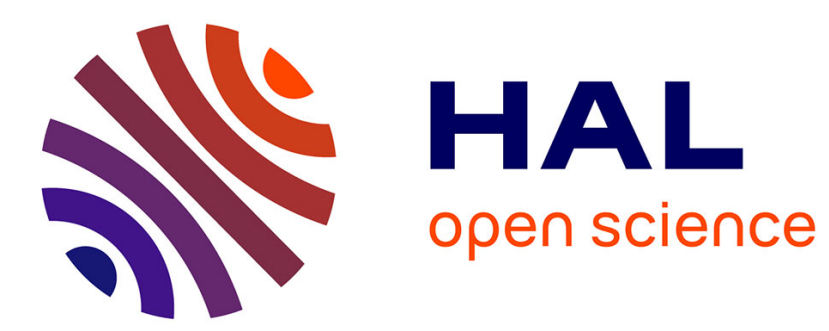

\title{
Analyses of a 426-Day Record of Seafloor Gravity and Pressure Time Series in the North Sea
}

S. Rosat, B. Escot, J. Hinderer, J.-P. Boy

\section{To cite this version:}

S. Rosat, B. Escot, J. Hinderer, J.-P. Boy. Analyses of a 426-Day Record of Seafloor Gravity and Pressure Time Series in the North Sea. Pure and Applied Geophysics, 2017, 175, pp.1793 - 1804. 10.1007/s00024-017-1554-6 . hal-01515466

\author{
HAL Id: hal-01515466 \\ https://hal.science/hal-01515466
}

Submitted on 14 Feb 2022

HAL is a multi-disciplinary open access archive for the deposit and dissemination of scientific research documents, whether they are published or not. The documents may come from teaching and research institutions in France or abroad, or from public or private research centers.
L'archive ouverte pluridisciplinaire HAL, est destinée au dépôt et à la diffusion de documents scientifiques de niveau recherche, publiés ou non, émanant des établissements d'enseignement et de recherche français ou étrangers, des laboratoires publics ou privés. 


\section{S. ROSAT, ${ }^{1}$ B. ESCOT,${ }^{1}$ J. HINDERER, ${ }^{1}$ and J.-P. BOY ${ }^{1}$}

Pure Appl. Geophys. 175 (2018), 1793-1804

https://doi.org/10.1007/s00024-017-1554-6

Abstract - Continuous gravity observations of ocean and solid tides are usually done with landbased gravimeters. In this study, we analyze a 426day record of time-varying gravity acquired by an ocean-bottom Scintrex spring gravimeter between August 2005 and November 2006 at the Troll A site located in the North Sea at a depth of $303 \mathrm{~m}$. Seabottom pressure changes were also recorded in parallel with a Paroscientific quartz pressure sensor. From these data, we show a comparison of the noise level of the seafloor gravimeter with respect to two standard land-based relative gravimeters: a Scintrex CG5 and a GWR Superconducting Gravimeter that were recording at the J9 gravimetric observatory of Strasbourg (France). We also compare the analyzed gravity records with the predicted solid and oceanic tides. The oceanic tides recorded by the seafloor barometer are also analyzed and compared to the predicted ones using FES2014b ocean model. Observed diurnal and semi-diurnal components are in good agreement with FES2014b predictions. Smallest constituents reflect some differ-ences that may be attributed to non-linearity occurring at the Troll A site. Using the barotropic TUGO-m dynamic model of sea-level response to ECMWF atmospheric pressure and winds forcing, we show a good agreement with the detided ocean-bottom pressure residuals. About $4 \mathrm{hPa}$ of standard deviation of remaining sea-bottom pressure are, however, not explained by the TUGO-m dynamic model.

Keywords: Seafloor gravimeter, seafloor pressure measurements, inverted-barometer response, oceanic tides, dynamic response of the oceans.

\section{Introduction}

There are very few available long records of timevarying gravity on the seafloor compared to landbased continuous gravity measurements. Seafloor observations are usually limited to spatial gravity surveys of short duration (e.g., Ballu et al. 1998; Zumberge et al. 2008). From the first marine gravity measurements (Beyer et al. 1966) to the latest ones (Sasagawa et al. 2008), the seafloor gravity precision has gained a factor of hundred. The necessity of precise models of the time-varying tidal signals for reservoir monitoring has motivated the installation of long-term seafloor gravity and pressure observations in the North Sea, in the frame of the Troll A gasreservoir monitoring program (Sasagawa et al. 2003). From August 14th, 2005 to November 3rd, 2006 an ocean-bottom Scintrex gravimeter (SN970439) and a Paroscientific quartz pressure sensor (model $31 \mathrm{~K}, \mathrm{SN}$ 74329) were measuring at a depth of $303 \mathrm{~m}$ on the North Sea floor (60.64227LN, 3.72417LE; see Fig. 1) nearly continuously (Sasagawa et al. 2008). The sensors are mounted in a single frame carried by a remotely operated vehicle (ROV). The instrument is called ROVDOG for remotely operated vehicle-deployed deep-ocean gravimeter.

The records contain two time-series of gravimetric and pressure data initially sampled at $1 \mathrm{~s}$ then decimated to $1 \mathrm{~min}$ after applying an antialiasing low-pass filter: the first from August 14th, 2005 to March 5th, 2006 and the second from March 25th, 2006 to November 3rd, 2006. The gap between the two series is due to mechanical maintenance (Sasagawa et al. 2008). In Fig. 2, we have plotted the seafloor gravity and pressure measurements before and after tidal analyses. As any relative Scintrex instrument, the seafloor gravimeter is affected by a strong non-linear drift. We decided to high-pass filter the gravity records with a cut-off period of 10 days in order to remove this trend before performing the analyses.

In a first part, we perform a noise level comparison with standard land-based gravimeters and barometer. Then, we compare the tidal analysis results with the predicted solid and oceanic tides. Thanks to the seafloor barometric records, we have a 

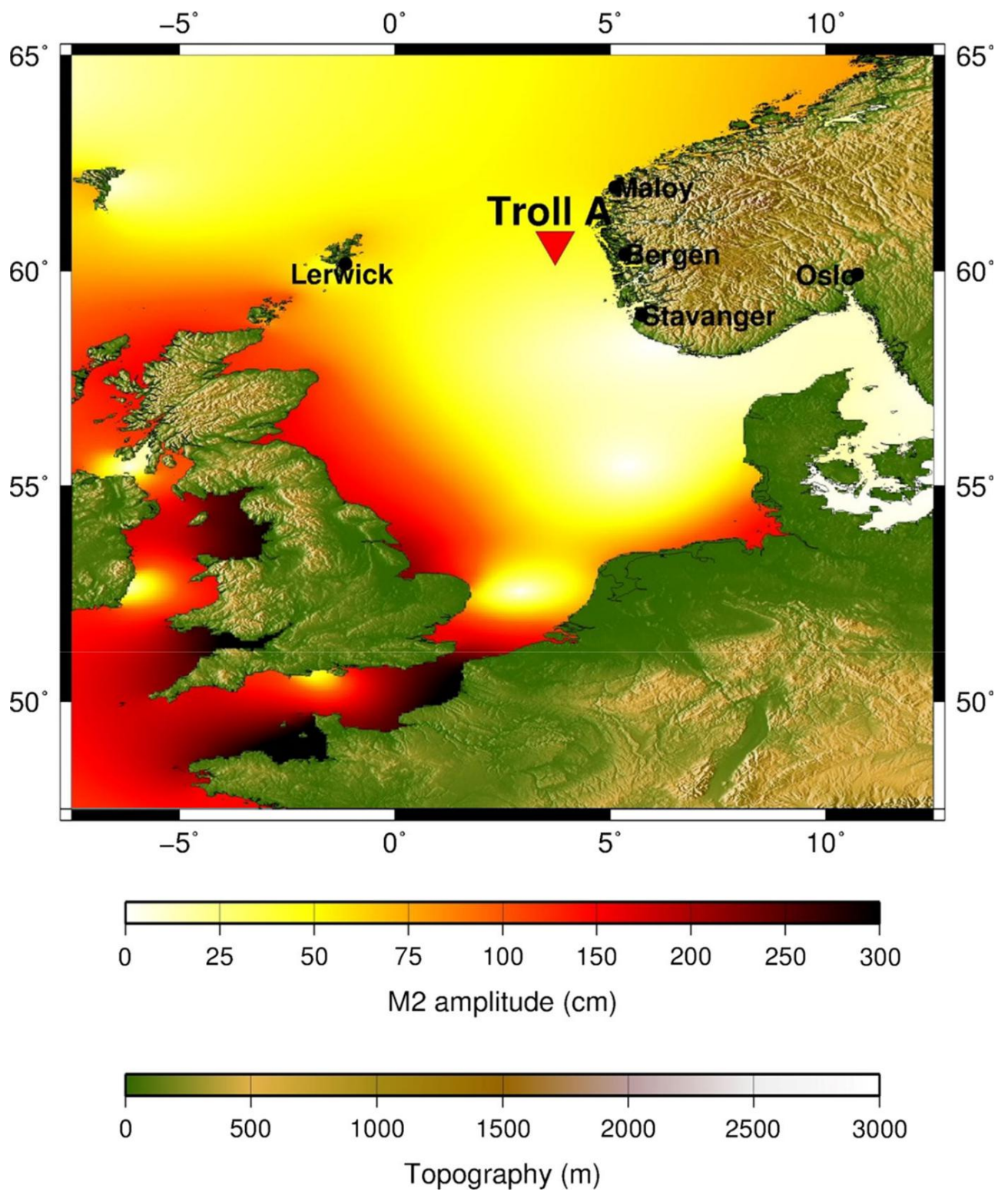

Figure 1

Map of the Troll A site where the seafloor gravimeter and barometer were deployed from August 2005 to November 2006. The amplitude of $\mathrm{M}_{2}$ tide from FES2014b ocean model is also plotted in $\mathrm{cm}$

direct measurement of oceanic tides that we compare with FES2014b (Carrère et al. 2015) tidal heights. Finally, we investigate the in situ dynamics of oceans by comparing the sea-bottom pressure data with the TUGO-m 2D (Toulouse Unstructured Grid Ocean model 2D, ex-MOG2D) modeling of the dynamic ocean response to ECMWF pressure and winds forcing (Carrère and Lyard 2003).

\section{Noise Level Analysis}

Knowledge of the noise level at a site is fundamental in the search for small signals or to infer the quality of a site or the precision of an instrument. With one instrument at a site it is not possible to separate the contribution of the instrument itself from the environmental noise. Here we have the possibility 
(a)
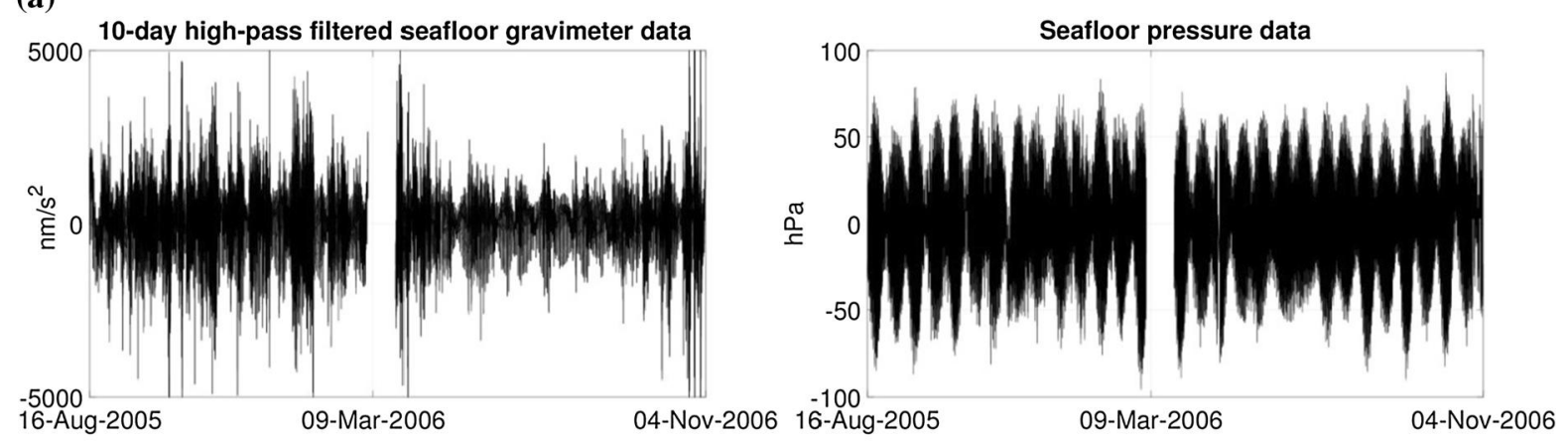

(b)

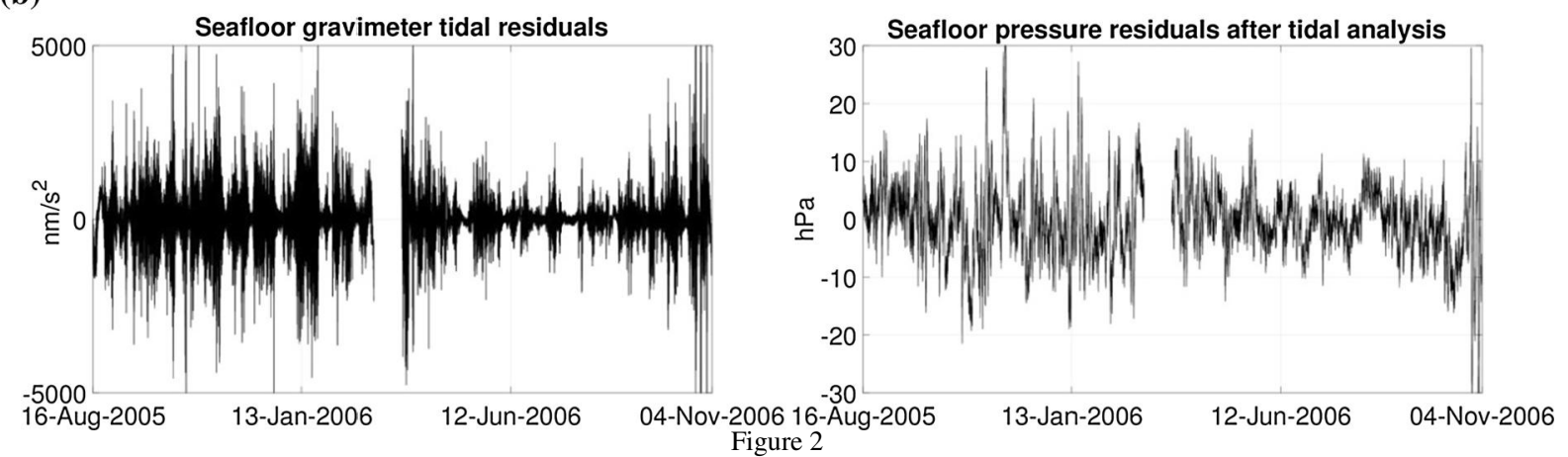

Seafloor records: a gravimetric records after a high-pass filtering with a cut-off period of 10 days (left plot) and pressure records (right plot); b gravimetric (left plot) and pressure (right plot) residuals after tidal analyses with ETERNA software

to compare the noise level of a relative Scintrex gravimeter installed on the sea bed with one installed on land. We may assume that the instrumental noise from one Scintrex to the other one is not so much different, nevertheless the noise coming from the ocean is expected to be much larger. The question is by how much a seafloor gravimeter is noisier than a land-based gravimeter. In that purpose of quantifying the noise, we compute power spectral densities (PSDs) using a Welch's overlapped segment aver-aging estimator on data sampled at $1 \mathrm{~min}$. These PSDs are obtained from fortnightly segments in order to represent the noise level at seismic and sub-seismic frequencies. For each fortnightly segment, the Welch periodogram is computed using a Hanning window on daily sections with a $50 \%$ overlap, leading to an average of 15 modified periodograms to produce a PSD estimate. Then, we compute the median of the distribution of PSDs obtained from 115 fortnightly segments (only 13 segments for the Scintrex CG5 at J9 since the available time-record is shorter). The median PSD means that the noise does not exceed this level $50 \%$ of the time.

The noise level of the seabed gravimetric record is compared in Fig. 3 with the noise levels of the superconducting gravimeter (SG-C026) and the Scintrex CG5 that were recording at the J9 gravimetric observatory of Strasbourg (France) (Rosat et al. 2015). The seismological NLNM reference noise model (Peterson 1993) and the more recent Global Seismic Network (GSN) noise model (Berger et al. 2004) are also plotted for reference. The NLNM corresponds to the lowest envelope of the PSDs computed from the GSN stations. The GSN noise model that Berger et al. (2004) have developed more recently is based on 118 GSN stations and is more complete than NLNM since they computed not only the minimum, but also the percentiles of PSD 


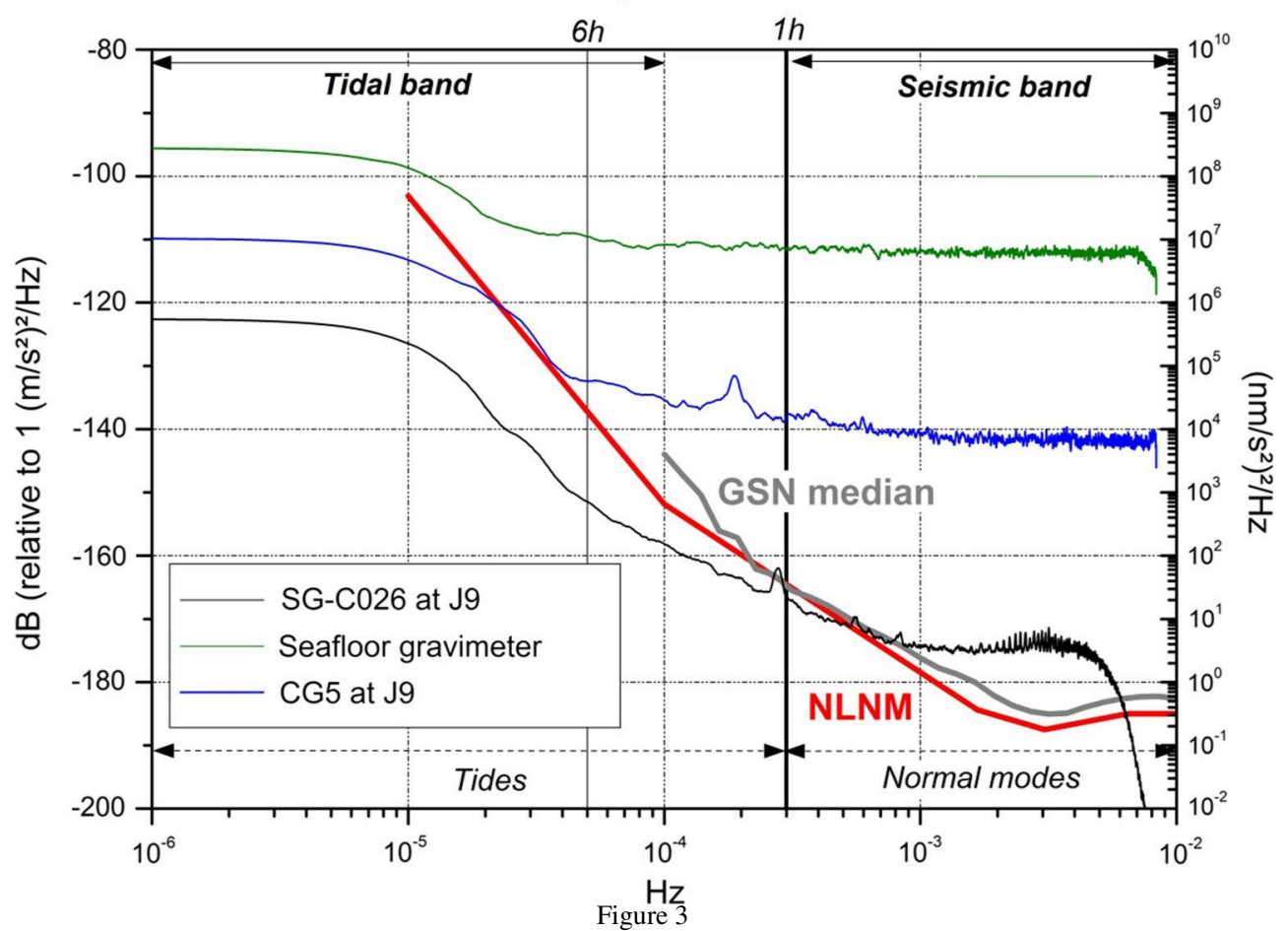

Median noise levels computed from fortnightly time windows for the SG-C026 and CG5 land gravimeters recording at the J9 gravimetric observatory of Strasbourg (France) and for the seafloor gravimeter recording at Troll A site. The PSDs were computed on the gravity residuals after a tidal analysis with ETERNA software. The low noise model (NLNM, in red) of Peterson (1993) and the median GSN noise model (in gray) of Berger et al. (2004) are also plotted for reference

distributions. Note that we used the median noise level from Berger et al. (2004), but those were computed from daily time-series while we used fortnightly ones to represent the noise level at subseismic frequencies. We can see on Fig. 3 that the median PSD for the SG-C026 follows well the NLNM while records from the seabed gravimeter are $50 \mathrm{~dB}$ noisier and the ones from the land CG5 are 20 $\mathrm{dB}$ noisier at $1-\mathrm{h}$ period. Note that the CG5 gravimeter was not operating at the time the seafloor gravimeter was recording while the SG was, so the environmental noises (mostly oceanic noise) seen by the SG and the CG5 at J9 are not the same. However, we also see, like in a previous study (Rosat et al. 2015), that the CG5 is $20 \mathrm{~dB}$ noisier than the SGC026 at 1-h period. The instrumental drifts of the land gravimeters were removed before the tidal analysis by fitting a linear trend.
The observed median noise level for the seafloor gravimeter is around $-110 \mathrm{~dB}$ (or $10^{7}\left(\mathrm{~nm} / \mathrm{s}^{2}\right)^{2} / \mathrm{Hz}=$ $0.1 \mathrm{mGal}^{2} / \mathrm{Hz}$ ) in the sub-seismic band between $10^{-4}$ $\mathrm{Hz}$ and the Nyquist frequency of $8.3310^{-3} \mathrm{~Hz}$. Sasagawa et al. (2003) had shown that the noise level at the Troll site was between $210^{-2}$ and 0.2 $\mathrm{mGal}^{2} / \mathrm{Hz}$ at $0.02 \mathrm{~Hz}$, respectively, during low and high swell states. Assuming the PSD remains flat towards higher frequencies, the value we have obtained in Fig. 3 lies in between but closer to high swell state, i.e., when significant wave heights can be observed (3-3.5 m). As shown in Table 1, the Troll A site indeed experienced some high swells during this period.

We can also compare the seabed pressure measurements from the Paroscientific model $31 \mathrm{~K}$ with the land-based barometric records at J9 from a Druck DPI145 barometer. To be able to compare with the 
Table 1

Meteorological data at the Troll A platform between October, 27 and November, 12006

\begin{tabular}{|c|c|c|c|c|c|}
\hline Date & $\begin{array}{l}\text { Wind } \\
\text { speed } \\
(\mathrm{m} / \mathrm{s})\end{array}$ & $\begin{array}{l}\text { Seafloor } \\
\text { pressure } \\
\text { variation } \\
(\mathrm{hPa})\end{array}$ & $\begin{array}{l}\text { Wave } \\
\text { ocean } \\
\text { height } \\
\text { (m) }\end{array}$ & $\begin{array}{l}\text { ECMWF } \\
+ \text { TUGO- } \\
\text { m pressure } \\
\text { variation } \\
(\mathrm{hPa})\end{array}$ & $\begin{array}{l}\text { ECMWF } \\
\text { pressure } \\
\text { variation } \\
(\mathrm{hPa})\end{array}$ \\
\hline $\begin{array}{c}2006 / 10 / 27 \\
03 \mathrm{~h}\end{array}$ & 20.6 & -28.5 & 6 & -24.3 & -31.7 \\
\hline $\begin{array}{c}2006 / 10 / 27 \\
18 \mathrm{~h}\end{array}$ & 6.2 & 41.3 & 1.7 & 23.4 & 6.24 \\
\hline $\begin{array}{c}2006 / 10 / 28 \\
15 \mathrm{~h}\end{array}$ & 5.7 & -9.6 & 2.1 & -6.22 & -4.7 \\
\hline $\begin{array}{c}2006 / 10 / 29 \\
18 \mathrm{~h}\end{array}$ & 9.8 & 18.6 & 2.6 & 9.6 & 3.18 \\
\hline $\begin{array}{c}2006 / 10 / 31 \\
15 \mathrm{~h}\end{array}$ & 25 & -16.1 & 7.5 & -11.8 & -31.7 \\
\hline $\begin{array}{c}2006 / 11 / 01 \\
15 \mathrm{~h}\end{array}$ & 7.7 & 42.4 & 2.1 & 22.45 & 14.1 \\
\hline
\end{tabular}

NLNM and with the seafloor gravimeter too, we compute the Newtonian attraction of the corresponding air column for the land barometer or water column for the seabed barometer, using the cylinder formula

$$
A=-2 \pi G \rho_{\mathrm{w}}\left[2 z-h-\sqrt{r^{2}+z^{2}}+\sqrt{r^{2}+(z-h)^{2}}\right],
$$

where $\rho_{\mathrm{w}}$ is the seawater density (or air density for the land barometer), $z$ is the height of the point inside the cylinder located on the axial symmetric axis at which the attraction is computed (in our case $z=0$ ), $r$ is the radius of the cylinder and $h$ is the height of the water column. We choose a value of $r$ much larger than the water height so that we tend towards the Bouguer approximation of $2 \pi \mathrm{G} \rho_{\mathrm{w}} h$.

The median PSDs for the ocean-bottom barometer are plotted in Fig. 4 with the seismological noise models and with the median PSD of the seafloor gravimeter.

It appears that the seabed pressure measurement is less noisy than the seabed gravimeter. It is known that bottom pressure is less sensitive to internal tides hence mostly records the barotropic two-dimensional water column (Ray 2013), while the gravimeter will integrate the three-dimensional water mass changes. Besides, the gravity residuals plotted in Fig. 1 illustrate the additional noise present in these records. We can also see that the seafloor barometer is $10 \mathrm{~dB}$ noisier than the land barometer at 1 -h period. A $10 \mathrm{~dB}$ difference corresponds to a factor 3 in amplitude, meaning that with the land barometer we can detect signals that are 3 times smaller than with the seabed barometer. Since the barometers are different, we cannot infer the part due to the instrumental noise from the contribution to the environmental noise, but we can assume that most of the noise difference is coming from the ocean noise, since ocean noise is larger in shallow waters than in the deep ocean. It is also larger at sites near the sea and J9 is located far, about $500 \mathrm{~km}$, from the North Sea.

\section{Tidal Analysis Results}

In this part we focus on the tidal analysis of the seafloor records. The seabed barometric records clearly show the oceanic tidal signal (see Fig. 2). These records can be analyzed to retrieve the tidal amplitudes and phases of the oceanic waves. For that we need to convert the seafloor barometric data from pressure variations $\Delta \mathrm{P}$ to equivalent tidal height changes $\xi$ using the hydrostatic equation:

$$
\Delta \mathrm{P}=\rho_{\mathrm{w}} \mathrm{g} \xi
$$

where $g$ is the mean gravity value and $\rho_{\mathrm{w}}$ the mean density of the water column. This simple and widely employed conversion may, however, be inadequate (Ray 2013). We have supposed a constant value of 1025 $\mathrm{kg} / \mathrm{m}^{3}$ for seawater density, but this simplification is questionable since it depends on temperature and salinity. Indeed compression of the water column should be considered by adding a correcting factor so that $\xi=\Delta \mathrm{P}\left(1-\mathrm{gH} / 2 \mathrm{c}^{2}\right) /\left(\mathrm{g} \rho_{\mathrm{W}}\right)$ with $\mathrm{c}$ the speed of sound and $\mathrm{H}$ the ocean depth (Ray 2013). This factor represents a $1 \%$ adjustment in deep water but less in shallow seas, where the conversion factor approaches unity. Since our site is at $303 \mathrm{~m}$ depth in the North Sea and according to Fig. 6 of Ray (2013), we can consider the usual Eq. (2) to convert bottom pressure into equivalent sea surface height with a negligible error. Moreover, seawater temperature profiles were collected to improve the seawater density model, but 


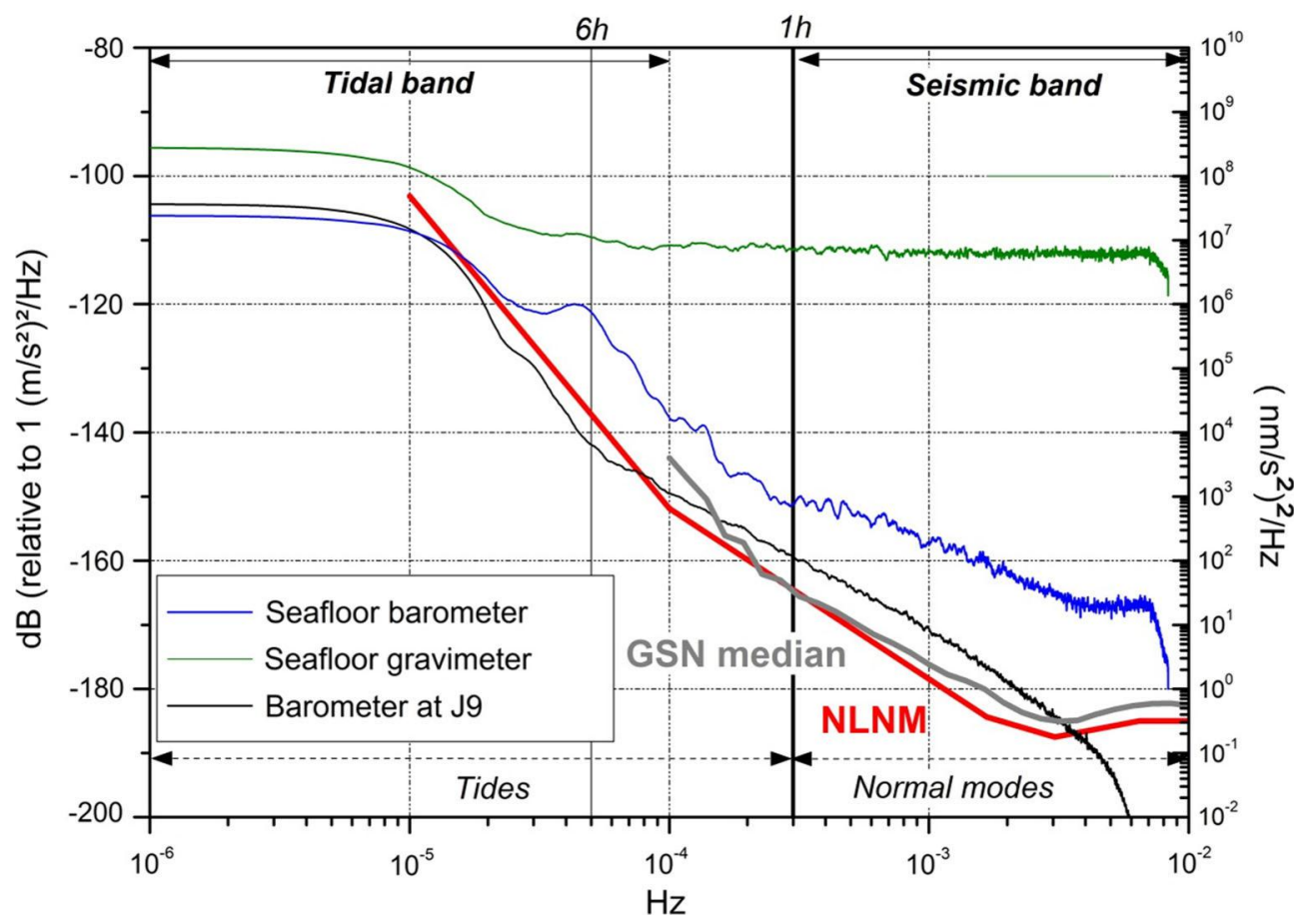

Figure 4

Median noise levels computed from fortnightly time windows for the land Druck DPI145 barometer recording at the J9 gravimetric observatory of Strasbourg (France) and for the seafloor barometer recording at Troll A site. The barometric pressures were converted into gravitational acceleration using the Bouguer approximation for comparison with the NLNM and with the median PSD of the seafloor gravimeter. The PSDs were computed on the residuals after a tidal analysis with ETERNA software for the seafloor gravimeter and barometer. The low noise model (NLNM, in red) of Peterson (1993) and the median GSN noise model (in gray) of Berger et al. (2004) are also plotted for reference

it turned out to be too small to affect the conversion from pressure to depth (Sasagawa et al. 2003).

The tidal analysis is performed with the ETERNA3.4 software (Wenzel 1996) which performs least-squares fit to tides and instrumental drift to give residual gravity and a polynomial drift function. The two time-series of, respectively, 203 and 223 days of seafloor records are analyzed as two separate blocks within ETERNA. For each block we remove a linear instrumental drift and use the HW95 tidal potential development (Hartmann and Wenzel 1995). The ETERNA analysis enables to retrieve the gravimetric $\delta$ factors and the $\kappa$ phase shifts of the selected waves with respect to the tidal potential for gravimetric records and the amplitudes and phase shifts of the selected waves for tidal height (pressure) records. We show the results of the $\delta$ factors for the diurnal waves obtained from the seafloor gravimeter on Fig. 5a. As for land gravimeters, we can observe an enhancement of the $\Psi_{1}$ wave due to the resonance with the free core nutation (FCN). However, the error bars are too large to attempt any retrieval of the FCN frequency from these data. These gravimetric factors represent the complete Earth's response to tidal forcing, that is to say the solid Earth tides and the ocean tides that we can compare to predicted ones. On Fig. 5, we have also plotted the predicted solid tides for an inelastic Earth model using the Dehant et al. (1999) model (noted hereafter DDW) in addition to the oceanic tides computed from FES2014b ocean model. For the gravimetric effects of the oceanic tides, we have taken into account the elastic 
(a)
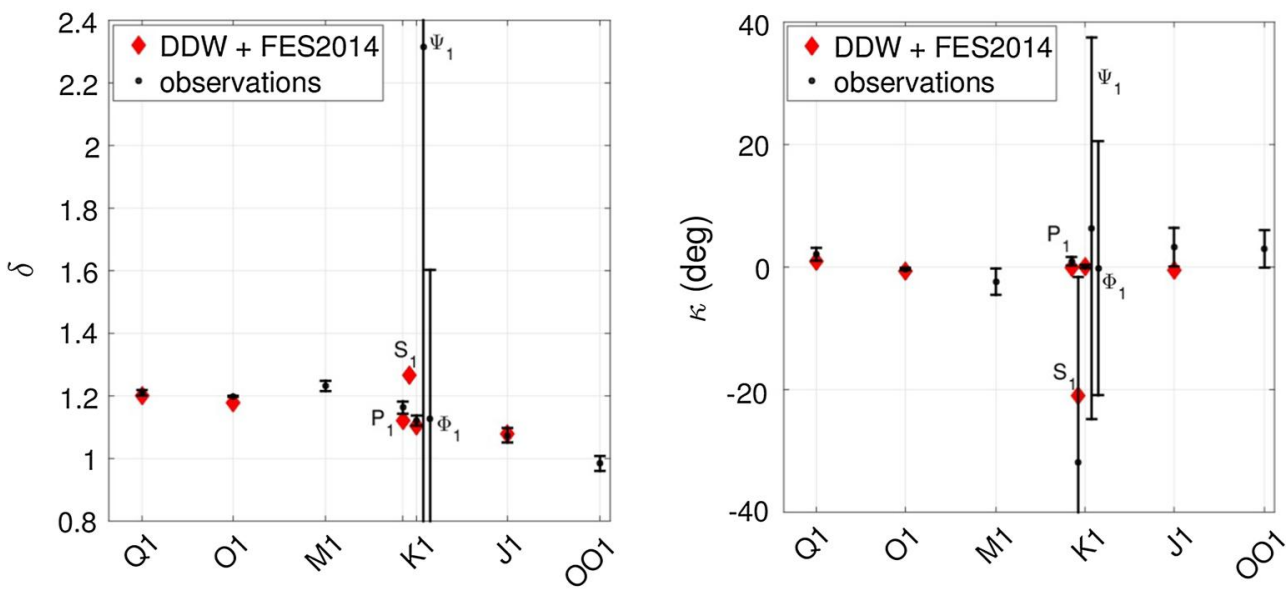

(b)

Ocean tides from seafloor barometer
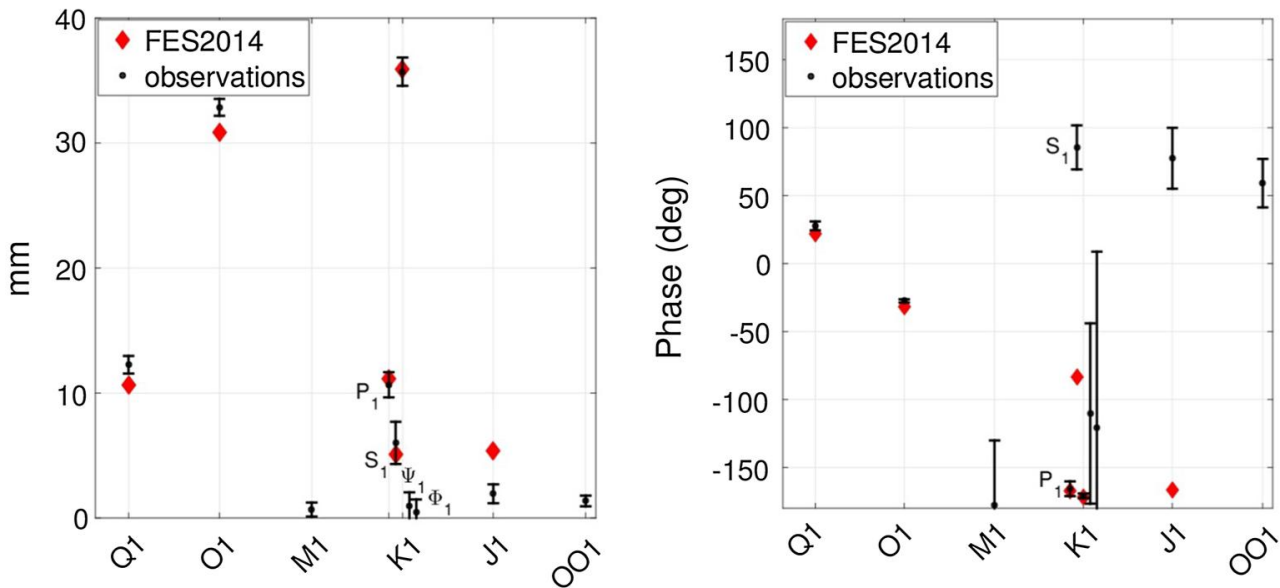

Figure 5

a Gravimetric amplitude factors for the 10 main diurnal waves obtained with ETERNA software by tidal analysis of the seafloor gravimeter data: amplitude factor $\delta$ (left plot) and phase shifts $\kappa$ (right plot) with respect to the predicted amplitude and phase for a solid Earth. Predicted tides are also plotted in red diamonds. They include the solid tides for a DDW (Dehant et al. 1999) inelastic Earth model and the total gravimetric effect (Newtonian attraction, elastic loading and local effect using a Bouguer approximation) from the oceanic tides using FES2014b model; b ocean tides amplitudes (left plot) and phases (right plot) for the 10 main diurnal waves obtained with ETERNA software by tidal analysis of the seafloor barometer data converted into ocean tide heights. The predicted amplitudes and phases for FES2014b ocean tide model are plotted in red diamonds. The HW95 tidal potential development (Hartmann and Wenzel 1995) was used as driving potential for all tidal analyses

loading, the direct Newtonian attraction and since the location is below the sea, we have added the local contribution from a Bouguer plate using the Eq. (1) and with FES2014b tidal amplitudes. Note that the $\delta$ amplitude factor for $\mathrm{S}_{1}$ is out of range in Fig. 5a with a value close to 6 since it contains the atmospheric thermal effect which is much larger than the gravitational $\mathrm{S}_{1}$ tide.

The seafloor pressure data are converted into water heights using Eq. (2) and then analyzed with ETERNA as ocean tide heights. The resulting amplitudes and phases with respect to the HW95 

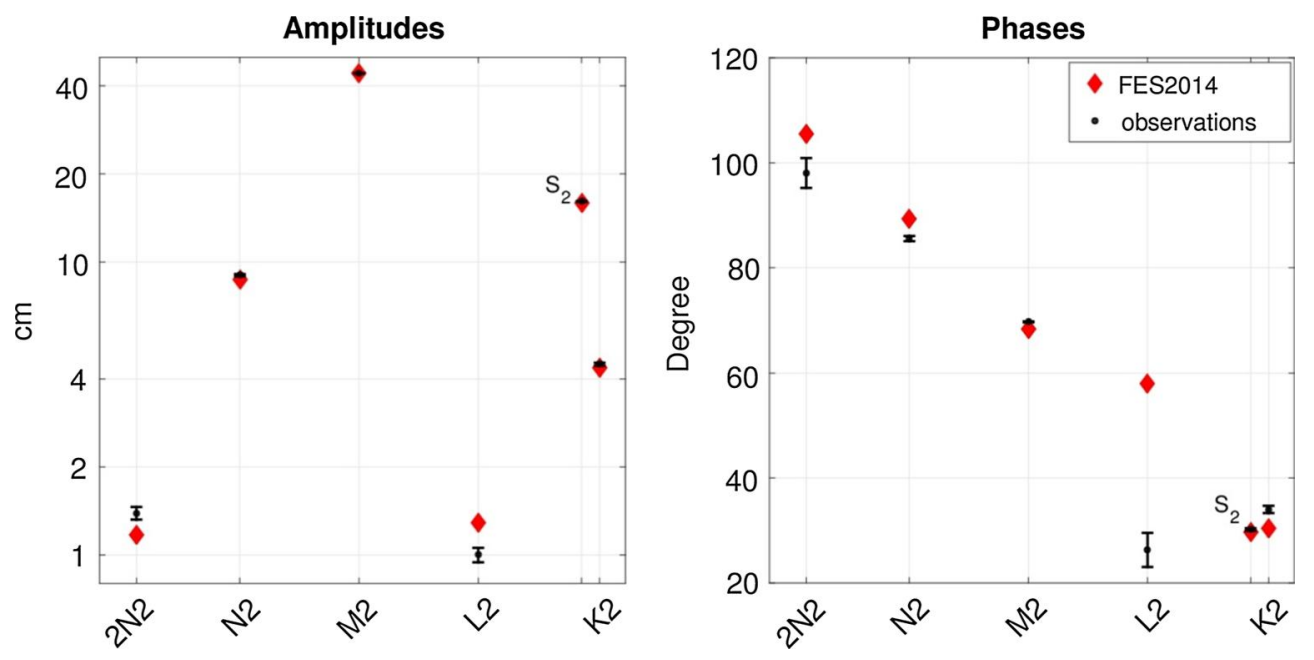

Figure 6

Amplitudes and phases for the semi-diurnal tidal waves analyzed with ETERNA from the seafloor barometer. The predicted amplitudes for FES2014b ocean tide model are plotted in red diamonds

(Hartmann and Wenzel 1995) driving tidal potential are plotted in Fig. 5b. We can compare them with the FES2014b (Carre're et al. 2015) ocean tidal model, in terms of amplitude and phase as shown in Fig. $5 \mathrm{~b}$ for the diurnal waves and in Fig. 6 for the semi-diurnal waves. The observed amplitudes and phases for the diurnal waves are in good agreement, within the error bars, with the predicted FES2014b model except for $\mathrm{J}_{1}$ component. The frequency of $\mathrm{J}_{1}$ is exactly equal to the difference of $\mathrm{M}_{2}$ and $\mathrm{Q}_{1}$ frequencies, so some potential non-linear interaction may affect this small component. Atmospheric tides perturb the sea-bottom pressure by adding a 1-2 $\mathrm{hPa}$ pressure to the measured one and by inducing a dynamic ocean response, the so-called radiational tide (Ray 2013). The $S_{1}$ amplitude in FES2014b is very close to the observed one, but the phase is very different. Large phase difference for small-amplitude waves like $\mathrm{J}_{1}$ and $\mathrm{S}_{1}$ is not surprising (e.g., Ray and Egbert 2004). The $\mathrm{S}_{2}$ tide is in good agreement between FES2014b and the sea-bottom observation with a difference of $1.7 \mathrm{~mm}$ meaning that the barometric tide over the oceans and the radiational tide are correctly modeled in FES2014b. As for the semi-diurnal waves, the largest difference occurs for the small L 2 constituent. For $\mathrm{M}_{2}$, the FES2014b amplitude is $44.147 \mathrm{~cm}$ and the observed $\mathrm{M}_{2}$ amplitude from analysis of sea-bottom pressure records is $43.854 \mathrm{~cm}$, resulting in a difference of $3 \mathrm{~mm}$, comparable to the difference obtained by Ray (2013) from worldwide sea-bottom pressure measurements.

\section{Ocean Response to Atmospheric Pressure Changes}

Under the influence of the atmospheric forcing, the ocean will respond in different ways depending on the time and space scales of the forcing (e.g., Ponte 1993). When the atmospheric pressure varia-tions occur on time-scales larger than 7 days, the ocean has enough time to balance this forcing by a water level change. This is the classical inverted barometer (IB) model, where a $1 \mathrm{hPa}$ of atmospheric pressure change will be compensated by a $1 \mathrm{~cm}$ sea-level variation, and thus no pressure change occurs at the sea bottom and ocean currents are negligible (Ponte et al. 1991; Wunsch and Stammer 1997; Egbert and Ray 2003). This IB static hypothesis was validated at long periods for instance by surface gravity observations (e.g., Bos et al. 2002; Boy et al. 2002). It is, however, well known that the sealevel response to air pressure changes does not always act like an ideal inverted barometer, particularly at periods shorter than 3 days and at high latitudes (Carre`re and Lyard 2003; Boy and Lyard 2008). One 
Transfer function: residual seafloor pressure vs $\left(\mathrm{P}_{\mathrm{ECMWF}^{+}} \rho_{\mathrm{w}} \mathrm{g} \delta \mathrm{h}_{\text {TUGO-m}}\right)$
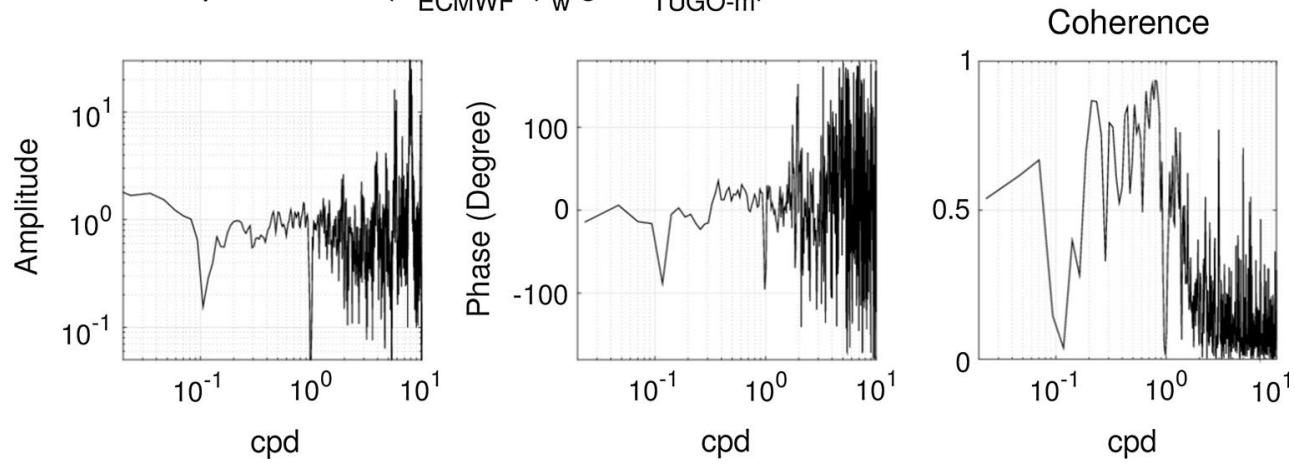

Figure 7

Transfer function (amplitude and phase) and magnitude squared coherence between residual seafloor pressure and TUGO-m (ex-MOG2D) sea-level response to ECMWF pressure and winds after subtraction of the IB response. Frequency unit is in cycle per day (cpd)

major reason for this dynamic response of the oceans at periods longer than 10 days is the wind effects which prevail, particularly at high latitudes and in the tropics (e.g., Fukumori et al. 1998). At seasonal timescales, the oceanic circulation is mostly forced by thermal effects, and the oceans cannot be considered as barotropic (Boy and Lyard 2008). Development of satellite altimetry like TOPEXPOSEIDON has enabled to quantify such deviations from the IB model (e.g., Ponte and Gaspar 1999).

In order to take into account the dynamic response of the oceans, a barotropic non-linear model based on 2dimension gravity waves model, called TUGO-m 2D (Toulouse Unstructured Grid Ocean model 2D, exMOG2D), has been developed by Lynch and Gray (1979) and Carrère and Lyard (2003). The governing equations of the model are the classical shallow water continuity and momentum equations. TUGO-m $2 \mathrm{D}$ is a barotropic model that represents the dynamic response of the oceans to atmospheric winds and pressure forcing from ECMWF pressure (noted PECMWF). The total ocean-bottom pressure should be given by:

$$
\mathrm{P}_{\mathrm{ECMWF}}+\rho_{\mathrm{w}} \mathrm{g} \delta \mathrm{h}_{\mathrm{TUGO}-\mathrm{m},}
$$

where $\delta h_{\mathrm{TUGO}} \mathrm{m}$ is the predicted dynamic sea-level change.

After removing the tidal effects, the sea-bottom pressure changes still include effects of the atmospheric mass changes (atmospheric pressure and winds), oceanographical components (e.g., seiches, waves), density variations of the water column due to changes of temperature and salinity and some possible seafloor displacement due to crustal deformation. To infer the part coming from the atmospheric pressure and winds, we first check the coherence between the TUGO-m sea-level changes from which we removed the hydrostatic load due to average height of the water column responding as an IB to the ECMWF pressure changes using Eq. (3) and the seafloor pressure residuals after ETERNA tidal analysis. As argued in Sect. 3, we neglect the changes of temperature and salinity. The magnitude squared coherence is represented in Fig. 7 and is given by:

$$
C_{x y}=\left|P_{x y}\right|^{2} /\left(P_{x x} P_{y y}\right),
$$

where $x$ is the dynamic part of the ocean response (PECMWF $\left.+\rho_{\mathrm{w}} \mathrm{g} \delta \mathrm{h}_{\mathrm{TUGO}} \mathrm{m}\right)$ and $y$ the seafloor pressure residuals after ETERNA tidal analysis. $\mathrm{P}_{\mathrm{Xx}}$ is the PSD estimate of $x, P_{y y}$ is the PSD estimate of $y$ and $\mathrm{P}_{\mathrm{xy}}$ is the cross-PSD between $\mathrm{x}$ and $\mathrm{y}$. The PSD is obtained using the Welch's averaged, modified periodogram method, i.e., the signals $\mathrm{x}$ and $\mathrm{y}$ are divided into eight sections with $50 \%$ overlap and tapered with a Ham-ming window. For each section, a modified periodogram is computed and the eight periodograms are averaged. 


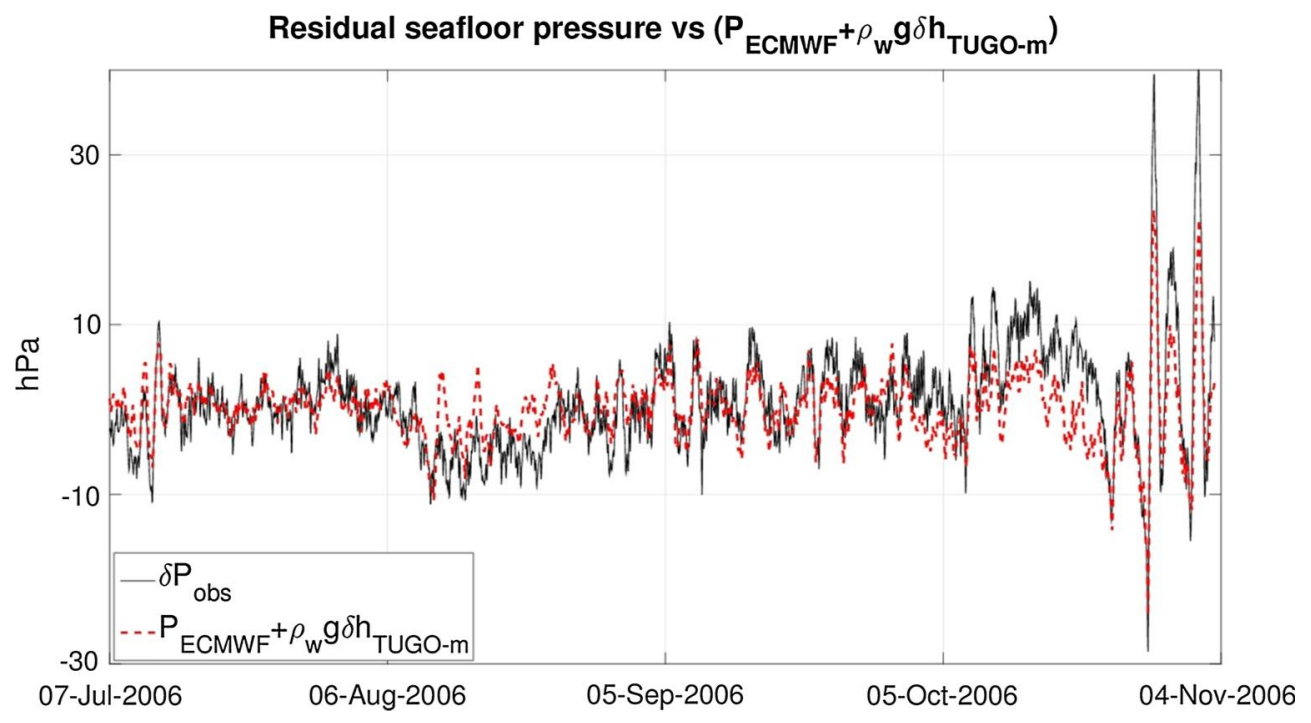

Figure 8

A 4-month comparison of the TUGO-m (ex-MOG2D) dynamic response of the oceans (after subtraction of the IB response from ECMWF pressure and winds forcing) and seafloor pressure residuals

The transfer function between the modeled ocean response and seafloor pressure residuals is computed in the same way by:

$$
T_{x y}(f)=P_{y x}(f) / P_{x x}(f) .
$$

The transfer function (amplitude and phase) is also plotted on Fig. 7.

Between 1 and 10 days the coherence is large (about 0.9 ), the phase of the transfer function is zero and the admittance is close to one. This means that the dynamic TUGO-m barotropic response of the ocean agrees with the sea-bottom pressure residuals as expected. At the period of 1 day, there is also a drop of coherence, associated with a large phase and an admittance close to zero. This is due to the removal of $\mathrm{S}_{1}$ tide during the tidal analysis of pressure data while it was not removed from the TUGO-m model. Between about 0.5 and 0.9 day, the coherence is large again, with a phase close to zero and an admittance close to one again. There is a good agreement between sea-bottom observations and TUGO-m. At periods shorter than 0.5 day, the coherence becomes weak as TUGO-m is not given for higher frequencies. Around a period of 10 days, we have a drop of coherence between the ocean dynamic response and the seafloor pressure residuals, with a very small admittance (amplitude of the transfer function) of 0.15 and a large phase close to -100 degrees. Indeed at periods longer than 10 days, the barotropic hypothesis within TUGO-m may not be appropriate anymore and thermal forcing becomes important.

An illustration of the good agreement between seafloor pressure residuals and the dynamic prediction is plotted in Fig. 8 with a stormy event that occurred at the end of October and early November 2006. The time scale concerned by this phenomenon is less than a day, so out of the IB approximation. We can see that there is no time-shift between the predicted TUGO-m dynamic response and the observed pressure changes and their amplitudes are very similar. The standard deviation of the difference is close to $4 \mathrm{hPa}(4 \mathrm{~cm})$ while the pressure data after tidal removal had a standard deviation of $5.5 \mathrm{hPa}$, so one part of the signal is coming from the dynamic ocean response to ECMWF pressure and winds, and the remaining comes from other meteorological effects that we cannot identify yet.

Wind speed and pressure variations associated to Fig. 8 are given in Table 1 . The meteorological data were provided by the Norwegian 
Meteorological service and the wave ocean heights come from radar data recorded at the Troll A platform. We can see from Table 1 that wind strength is correlated with sea level, with the pressure variations recorded by the seafloor barometer, and with ECMWF and ECMWF + TUGO-m predictions. Indeed, strong winds fit with low pressure and weak winds fit well with high pressure. Hence the event of Fig. 8 illustrates a dynamic ocean response driven by winds that is well modeled in TUGO-m. Boy and Lyard (2008) have also shown a good agreement between tide gauge measurements and TUGO-m sea surface height variations during two large storm surges in the North Sea. We observe, however, a 4$\mathrm{hPa}$ difference in standard deviation between the ocean-bottom pressure data and TUGO-m model. The time-scale of this storm is too short to consider a thermal forcing as a possible explanation for the remaining seafloor pressure. The spatial resolution of TUGO-m is $0.25^{\circ}$ which may be not precise enough to represent local effects at the Troll A site that may induce additional sea-bottom pressure.

\section{Conclusion}

Observed ocean tides at Troll A site with the seafloor barometer are in good agreement with FES2014b ocean tide model for the diurnal and semidiurnal waves. Some non-linearity may explain the noticed differences for some small constituents like $\mathrm{J}_{1}$. After removing tides, the standard deviation of the barometric residuals at Troll A decreased from 34 to $5.5 \mathrm{hPa}$. After removing the TUGO-m dynamic response of the oceans to ECMWF pressure and winds forcing, the standard deviation further decreased to nearly $4 \mathrm{hPa}$ (equivalent to $4 \mathrm{~cm}$ of seawater height). The in situ seafloor pressure observations clearly detect the part due to the dynamic response of the oceans to atmospheric pressure and winds forcing as modeled by TUGO-m. Other sources of sea-bottom pressure changes have, however, not yet been identified to explain the remaining sea-bottom pressure signal.

\section{Acknowledgements}

The authors acknowledge the suggestions of two anonymous reviewers that contributed to significantly improve this manuscript. We also thank David Crossley for his re-reading and suggested corrections to this paper. We are grateful to Glenn Sasagawa as a data contributor and to Ola Eiken for their useful information about the data and about the site measurement. This seafloor dataset was acquired by Scripps, under research contract with Statoil. Statoil is recognized as a sponsor of the data collection, and also for help with connecting cables and recording on the Troll A platform. Historical wind speed data were provided by the Norwegian Meteorological service at http://www.yr.no/place/Norway/Hav/Troll_A/ and the wave ocean heights come from radar data recorded on the Troll A platform. The General Mapping Tools (Wessel and Smith 1998) was used for plotting the map.

\section{REFERENCES}

Ballu, V., Dubois, J., Deplus, G. C., Diament, M., \& Bonvalot, S. (1998). Crustal structure of the Mid-Atlantic Ridge south of the Kane fracture zone from seafloor and sea surface gravity data. Journal of Geophysical Research, 103, 2615-2631.

Berger, J., Davis, P., \& Ekstro“m, G. (2004). Ambient Earth noise: a survey of the Global Seismographic Network. Journal of Geophysical Research, 109, B11307. doi:10.1029/2004JB003408.

Beyer, L. A., von Huene, R. E., McCulloh, T. H., \& Lovett, J. R. (1966). Measuring gravity on the sea floor in deep water. Journal of Geophysical Research, 71(8), 2091-2100.

Bos, M. S., Baker, T. F., Rothing, K., \& Plag, H.-P. (2002). Testing ocean tide models in the Nordic seas with tidal gravity obser-vations. Geophysical Journal International, 150, 687-694.

Boy, J.-P., Gegout, P., \& Hinderer, J. (2002). Reduction of surface gravity data from global atmospheric pressure loading. Geophysical Journal International, 149, 534-545.

Boy, J.-P., \& Lyard, F. (2008). High-frequency non-tidal ocean loading effects on surface gravity measurements. Geophysical Journal International, 175, 35-45.

Carrère, C., \& Lyard, F. (2003). Modeling the barotropic response of the global ocean to atmospheric wind and pressure forcingcomparisons with observations. Geophysical Research Letters, 30(6), 1275. doi:10.1029/2002GL016473. 
Carrère, L., Lyard, F., Cancet, M., A. Guillot, 2015. FES 2014, a new tidal model on the global ocean with enhanced accuracy in shallow seas and in the Arctic region, Geophysical Research Abstracts, 17, EGU2015-5481-1.

Dehant, V., Defraigne, P., \& Wahr, J. M. (1999). Tides for a convective Earth. Journal of Geophysical Research, 104, 10351058.

Egbert, G. D., \& Ray, R. D. (2003). Deviation of long period tides from equilibrium: kinematics and geostrophy. Journal of Physical Oceanography, 33, 822-839.

Fukumori, I., Raghunath, R., \& Fu, L.-L. (1998). Nature of global large-scale sea level variability in relation to atmospheric forcing: a modeling study. Journal of Geophysical Research, 103(C3), 5493-5512.

Hartmann, T., \& Wenzel, H.-G. (1995). The HW95 tidal potential catalogue. Geophysical Research Letters, 22(24), 3553-3556.

Lynch, D. R., \& Gray, W. G. (1979). A wave equation model for finite element tidal computations. Computers \& Fluids, 7, 207228 .

Peterson J., 1993. Observations and Modelling of Seismic Background Noise. Open-File Report 93-332. U.S. Department of Interior, Geological Survey, Albuquerque, NM.

Ponte, R. M. (1993). Variability in a homogeneous global ocean forced by barometric pressure. Dynamics of Atmospheres and Ocean, 18, 209-234.

Ponte, R. M., \& Gaspar, P. (1999). Regional analysis of the inverted barometer effect over the global ocean using TOPEX/ POSEIDON data and model results. Journal of Geophysical Research, 104(C7), 15587-15601.

Ponte, R. M., Salstein, D. A., \& Rosen, R. D. (1991). Sea level response to pressure forcing in a barotropic numerical model. Journal of Physical Oceanography, 21, 1043-1057.
Ray, R. D. (2013). Precise comparisons of bottom-pressure and altimetric ocean tides. Journal of Geophysical Research Oceans, 118, 4570-4584. doi:10.1002/jgrc.20336.

Ray, R. D., \& Egbert, G. D. (2004). The global S 1 tide. Journal of Physical Oceanography, 34, 1922-1935.

Rosat, S., Calvo, M., Hinderer, J., Riccardi, U., Arnoso, J., \& Zürn, W. (2015). Comparison of the performances of different Spring and Superconducting Gravimeters and a STS-2 Seismometer at the Gravimetric Observatory of Strasbourg, France. Studia Geophysica et Geodaetica, 59, 58-82.

Sasagawa, G. S., Crawford, W., Eiken, O., Nooner, S., Stenvold, T., \& Zumberge, M. A. (2003). A new seafloor gravimeter. Geophysics, 68, 544-553.

Sasagawa, G., Zumberge, M., \& Eiken, O. (2008). Long-term seafloor tidal gravity and pressure observations in the North Sea: testing and validation of a theoretical tidal model. Geophysics, 73(6), 143-148.

Wenzel, H. G. (1996). The Nanogal Software: earth tide data processing package ETERNA 3.30. Bull. Inf. Mare'es Terrestres, 124, 9425-9439.

Wessel, P., \& Smith, W. H. F. (1998). New, improved version of the Generic Mapping Tools released. EOS Transactions American Geophysical Union, 79(47), 579.

Wunsch, C., \& Stammer, D. (1997). Atmospheric loading and the oceanic "inverted barometer'" effect. Reviews of Geophysics, 35, 79-107.

Zumberge, M., Alnes, H., Eiken, O., Sasagawa, G., \& Stenvold, T. (2008). Precision of seafloor gravity and pressure measurements for reservoir monitoring. Geophysics, 73(6), 133-141. 